\title{
Fusión de agua y color en la obra de Mirna Ocádiz Soto
}

\author{
Enrique Méndez-Sosa
}

\begin{abstract}
En cada acuarela encuentra una feliz aventura de voces silenciosas que son torrentes de velos transparentes controlados por el magistral manejo de su pincel místico y que con pinceladas logra que el color se exprese por sí mismo para crear atmósferas de luz y bellos efectos cromáticos.
\end{abstract}

Ignacio Barrios

$\mathrm{L}$ a delicadeza y transparencia de la acuarela se logra mediante la combinación de pigmentos en pasta o en forma líquida con el aglutinante vital: el agua.

Esta técnica se basa en la superposición de capas transparentes o lavados, utilizando la blancura del papel para obtener efectos de reflejos y toques de luz. A medida que se incrementa la saturación de pigmento en las veladuras o transparencias usadas en los diferentes niveles, el color se vierte en tonalidades más profundas sobre el lienzo jugando con una gama de claroscuros que delinean la apariencia sutil, maravillosa y poética de la figura o modelo representado.

La selección de pinturas que aquí presentamos, pertenecientes a la proverbial obra de Mirna Ocádiz, engloba con delicadeza la pasión y sensibilidad de la artista toluqueña. La disrupción en la técnica tradicional provoca en la trama y urdimbre de sus telas y papel una atmósfera peculiar que oscila entre lo terrenal y lo etéreo. Las acuarelas, sus veladuras y claroscuros, revelan provocadoras escenas donde el fuego, el viento, el frío y el agua tienden hacia lo tectónico, la iluminación radiante y la penumbra.

En el trabajo de esta excepcional pintora encontramos manifestaciones de algarabía, nostalgia, paz, meditación, contemplación, recuerdos, sueños y revelaciones que se concretan en una explosión de pasión tierna y a la vez violenta. En cada cuadro tropezamos con un uso abundante de las formas doctas del arte, una expresión realista y al mismo tiempo abstracta, abastecida de versatilidad gracias al complejo manejo del color que se destaca por múltiples tonalidades, gamas, matices y destellos característicos. 
Y qué decir de aquellas texturas que remiten a la petrificación del fósil como sustancia orgánica que se encuentra en los antiguos depósitos sedimentarios de la corteza terrestre, y que aparecen aquí en forma de celosías orgánicas, con apariencia de hojarasca. Gracias a esta técnica, lo que podríamos llamar humus contribuye al desarrollo del trazo, de la expresión formal y de la peculiar interpretación del mundo de quien pinta. Las texturas constituyen una veladura más en este desfile de atmósferas y pensamientos que enmarcan la hazaña plástica de Mirna Ocádiz, mujer sensible y apasionada por el arte de la acuarela.

Algunos de los paisajes representados por la pintora mexiquense revelan una pasión por las ciudades lacustres e iridiscentes, como Venecia. Otro lienzo resalta la presencia geométrica y enigmática de Santa Sofía, en Estambul. Un desarrollo volumétrico de esferas y minaretes visto desde el mar del Bósforo es el tema de uno de los retratos, donde el tono de la luz varía de acuerdo con el ángulo desde el cual se observa. El agua, el cielo, la tierra, lo tornasolado de los elementos y las manchas

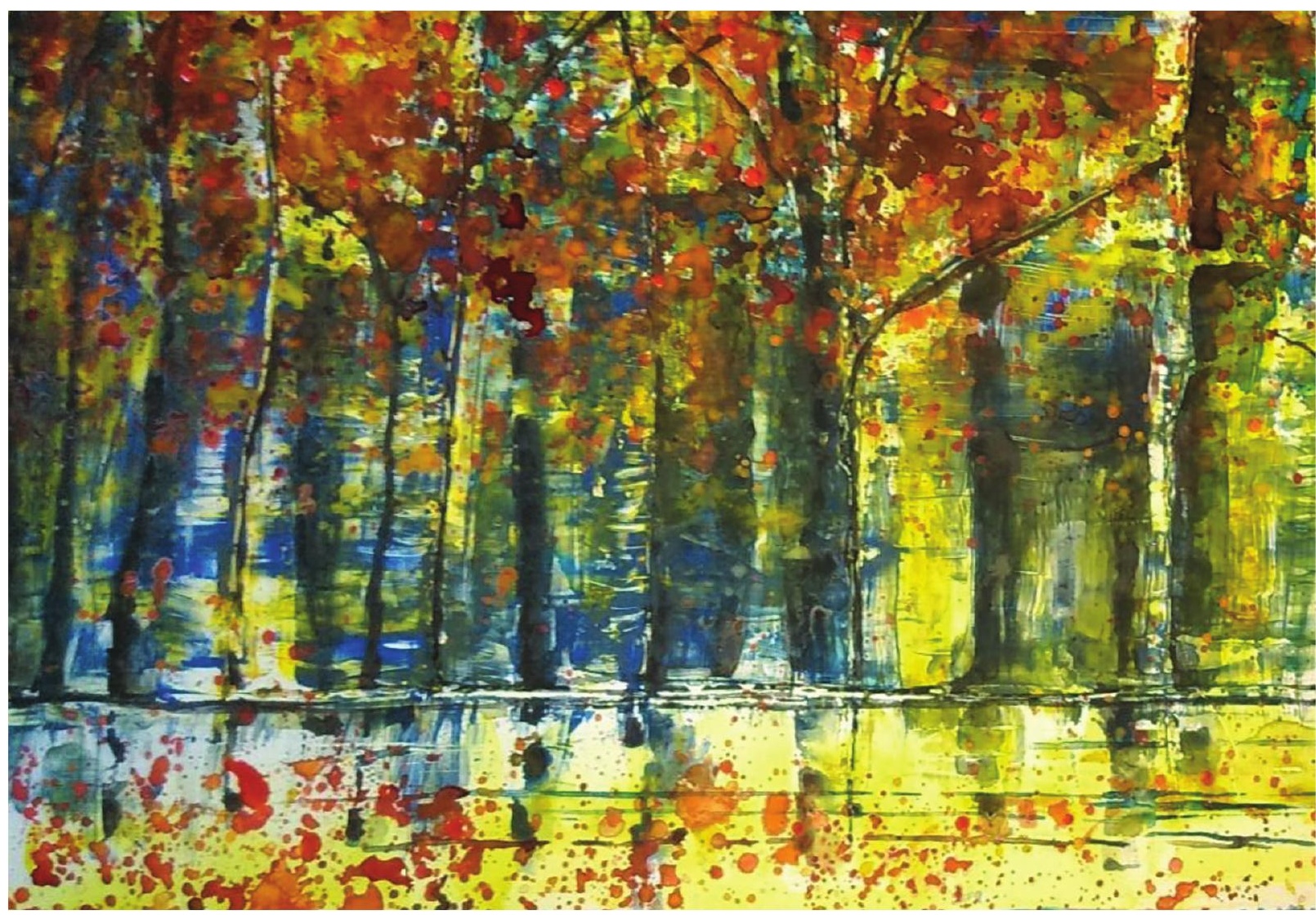

Arboleda en limón (2019). Acuarela con acrílico sobre papel de roca: Mirna Ocádiz-Soto. Prohibida su reproducción en obras derivadas. 
a manera de pixeles minúsculos que vibran en colores otoñales, de primavera y de cierzo invernal, constituyen un collage de emplazamientos urbanos que promueve la belleza de la arquitectura monumental.

Cabe resaltar la luminosidad que reflejan los cuadros de San Francisco y Montreal, los cuales enfatizan la evolución tecnológica y carácter contemporáneo de ambas ciudades. Estos elementos contrastan con la arquitectura vernácula, el candor musical, el ritmo acompasado, la armonía y la melodía del color que remiten a las poblaciones de América, en específico, la línea austral de este hermoso continente. Destaca también el folclor cosmopolita de Curitiba, ciudad que aparece retratada en medio de un atardecer candoroso.

La reflexión sobre el patrimonio también forma parte de las obras de esta hábil artista plástica. En ellas se manifiesta una imagen audaz e inocente de la relación entre vanos y macizos.

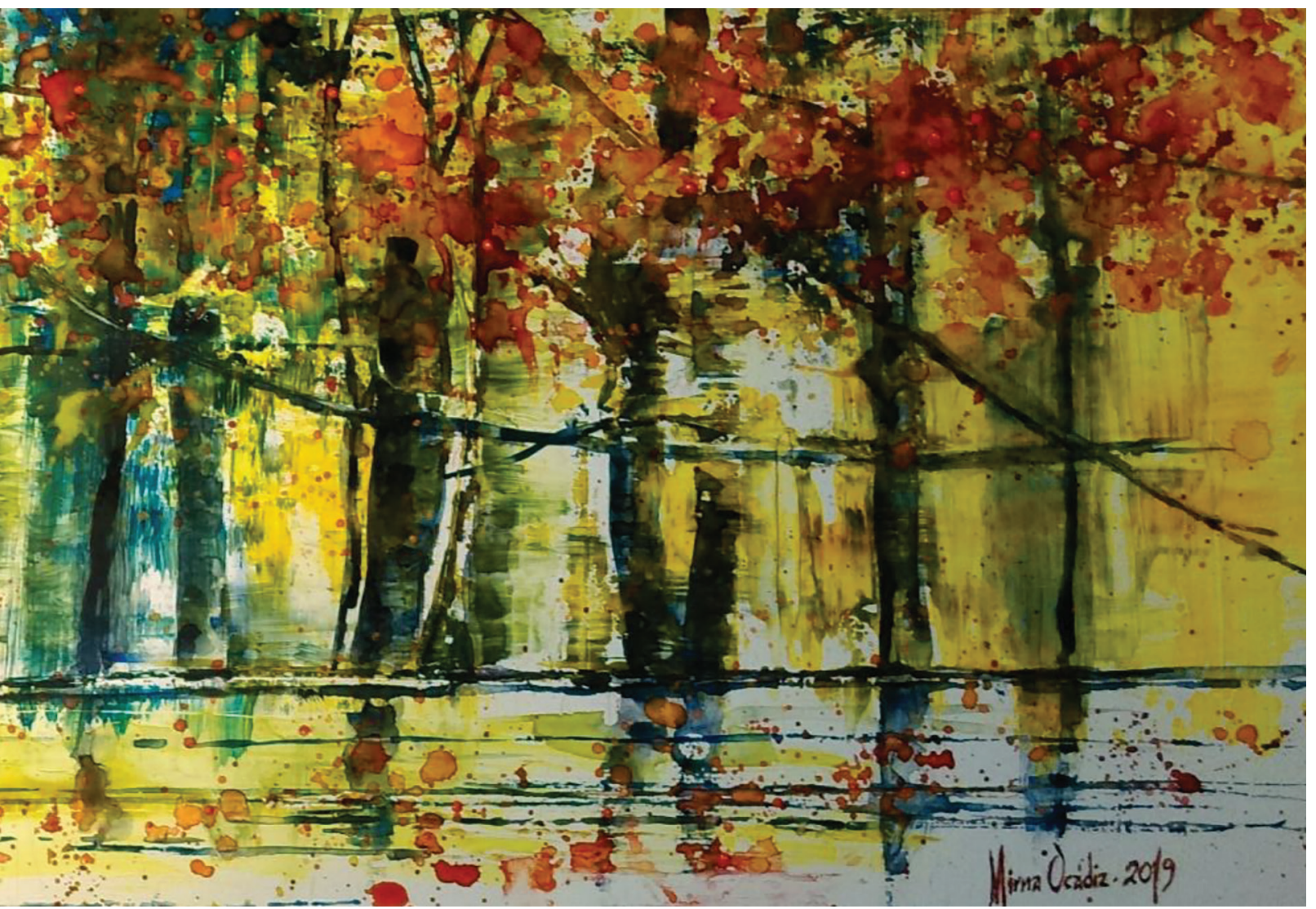




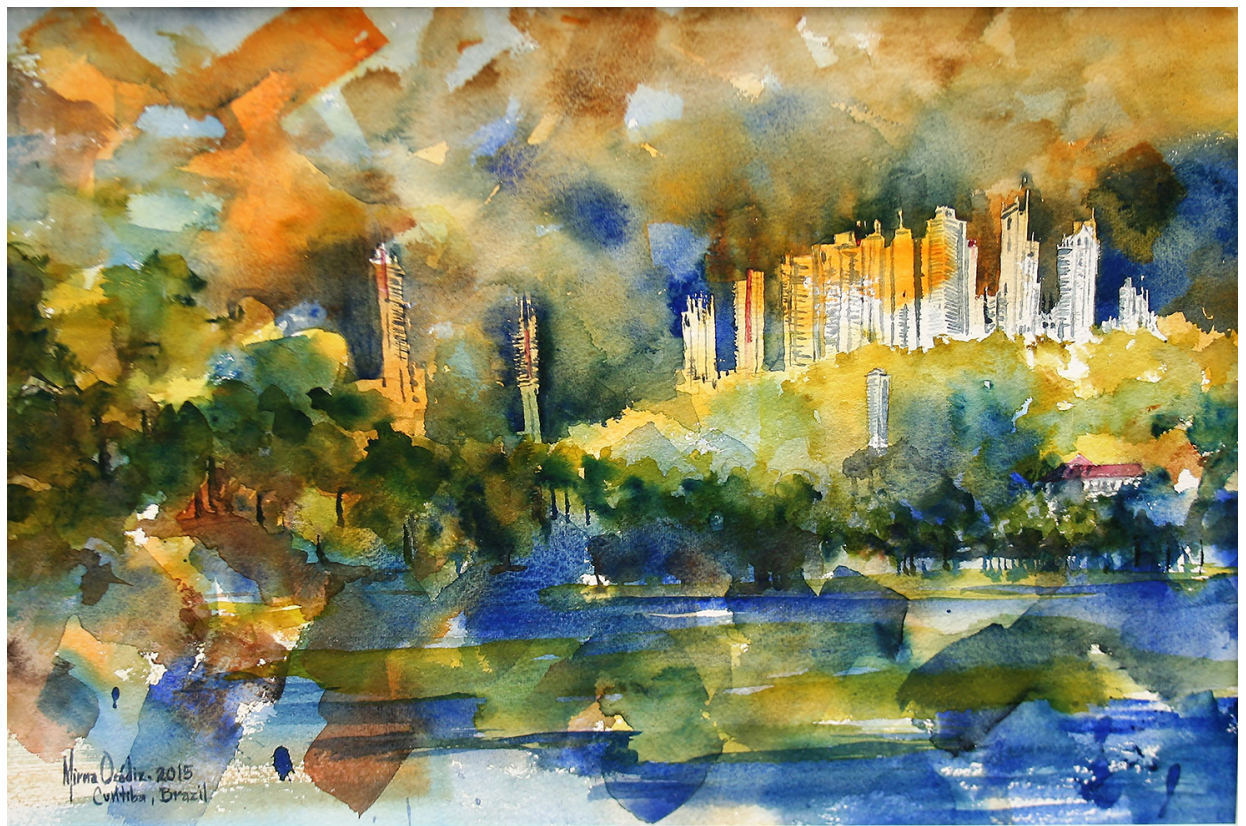

Curtiba, Brazil (2015). Acuarela sobre papel de algodón: Mirna Ocádiz-Soto. Prohibida su reproducción en obras derivadas.

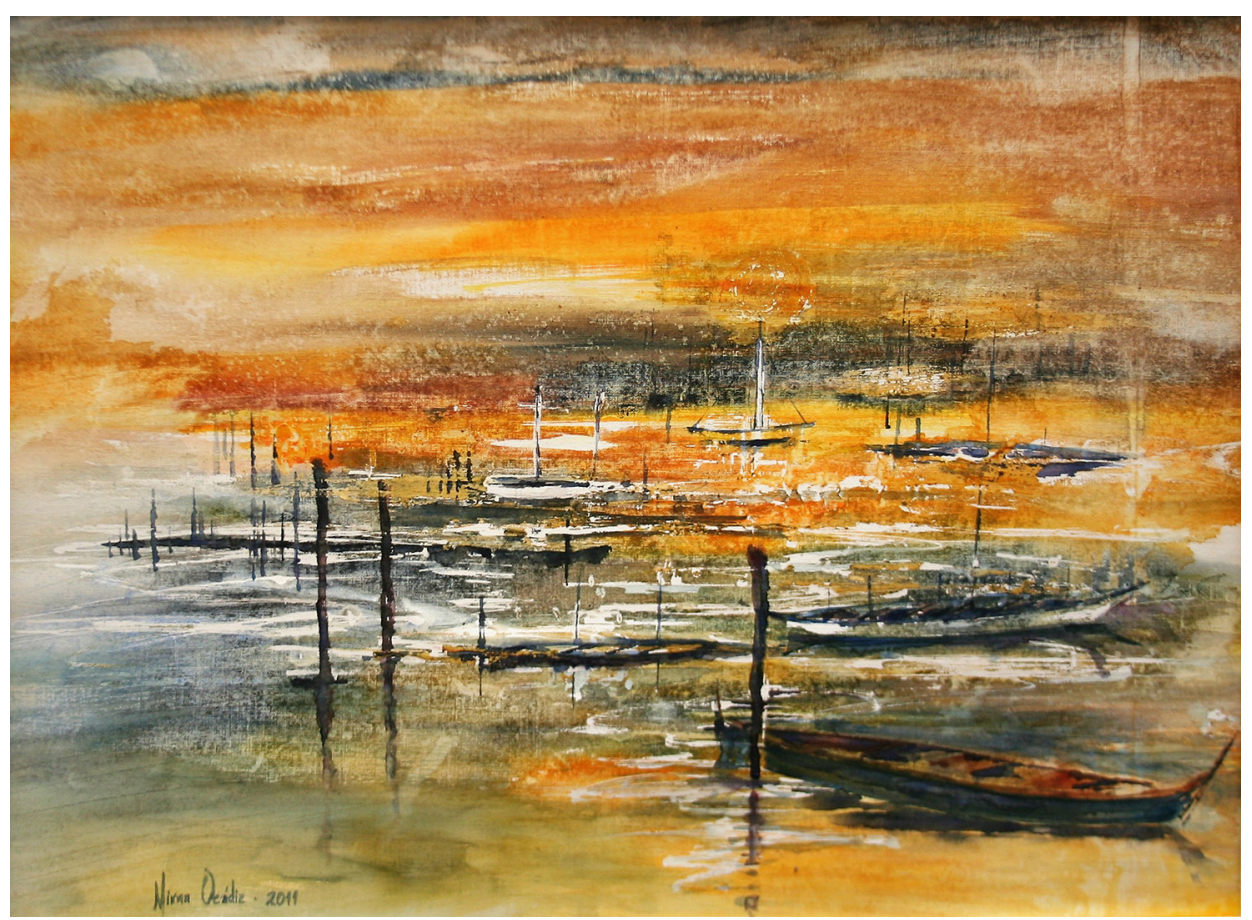

Atardecer en Vallarta (2011). Acuarela sobre tela: Mirna Ocádiz-Soto.

Prohibida su reproducción en obras derivadas. 


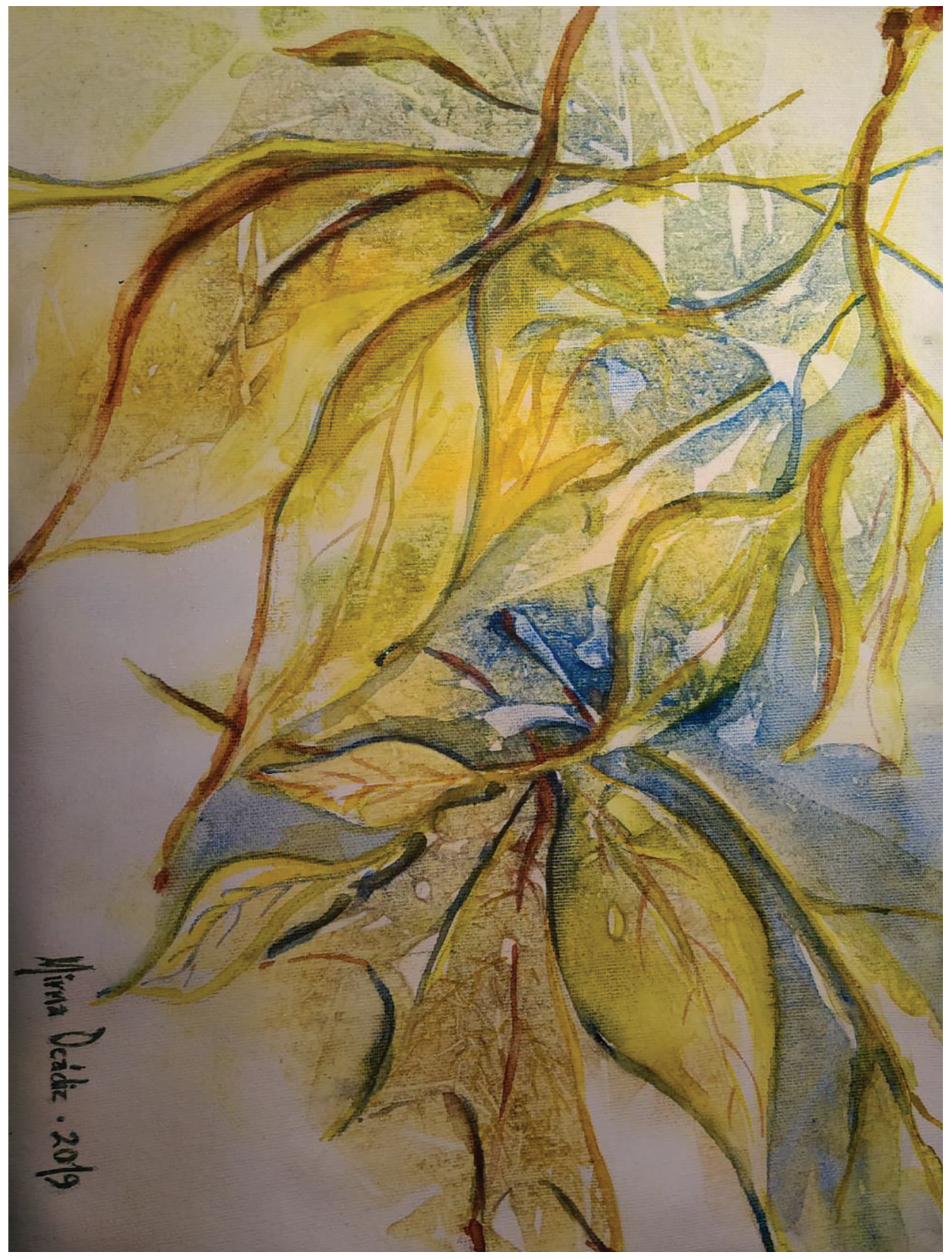

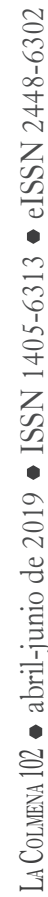

Hojas 1 (2019). Acuarela sobre tela: Mirna Ocádiz-Soto.

Prohibida su reproducción en obras derivadas. 


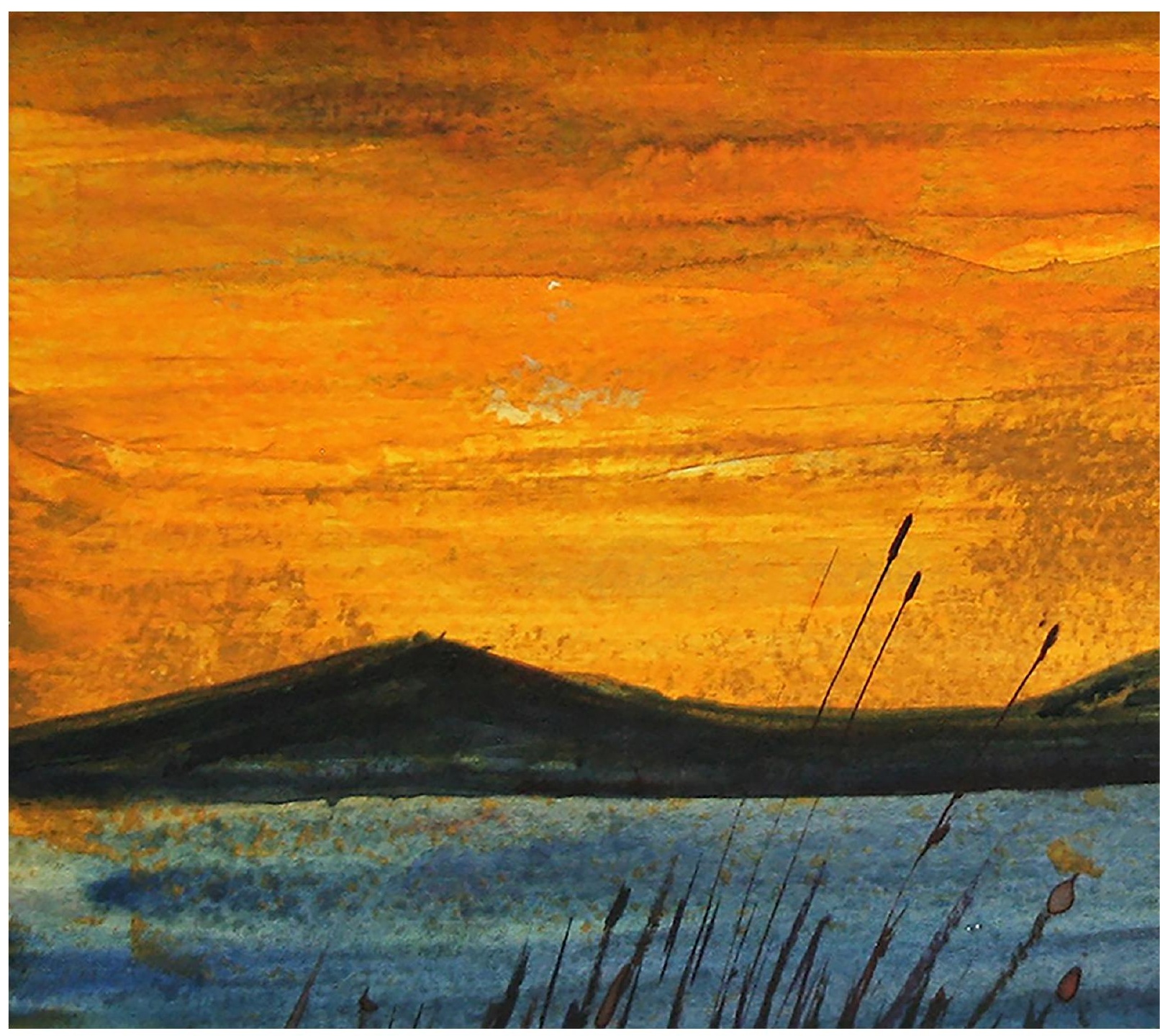

Atardecer (2018). Acuarela con acrílico sobre tela: Mirna Ocádiz-Soto. Prohibida su reproducción en obras derivadas. 


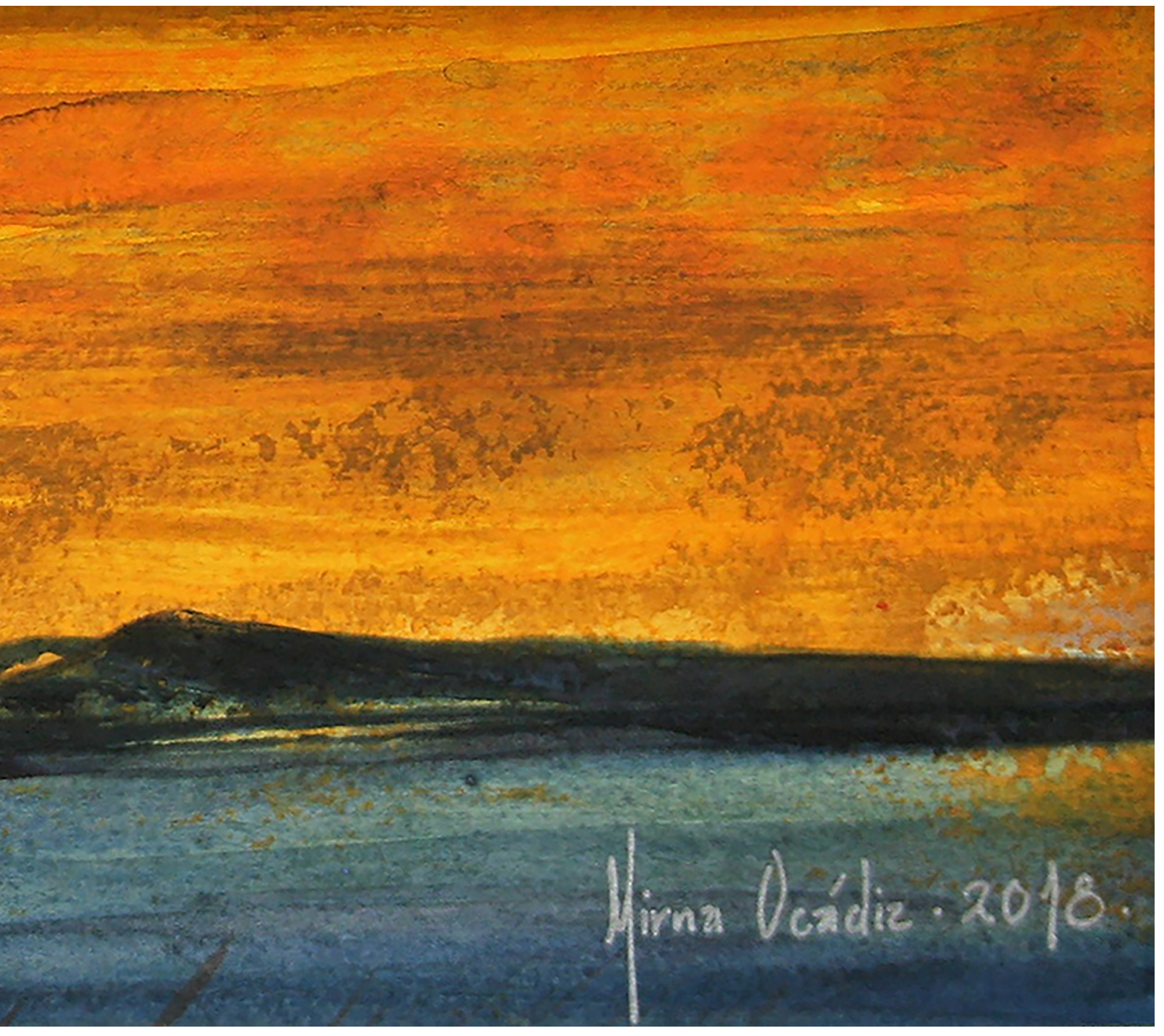




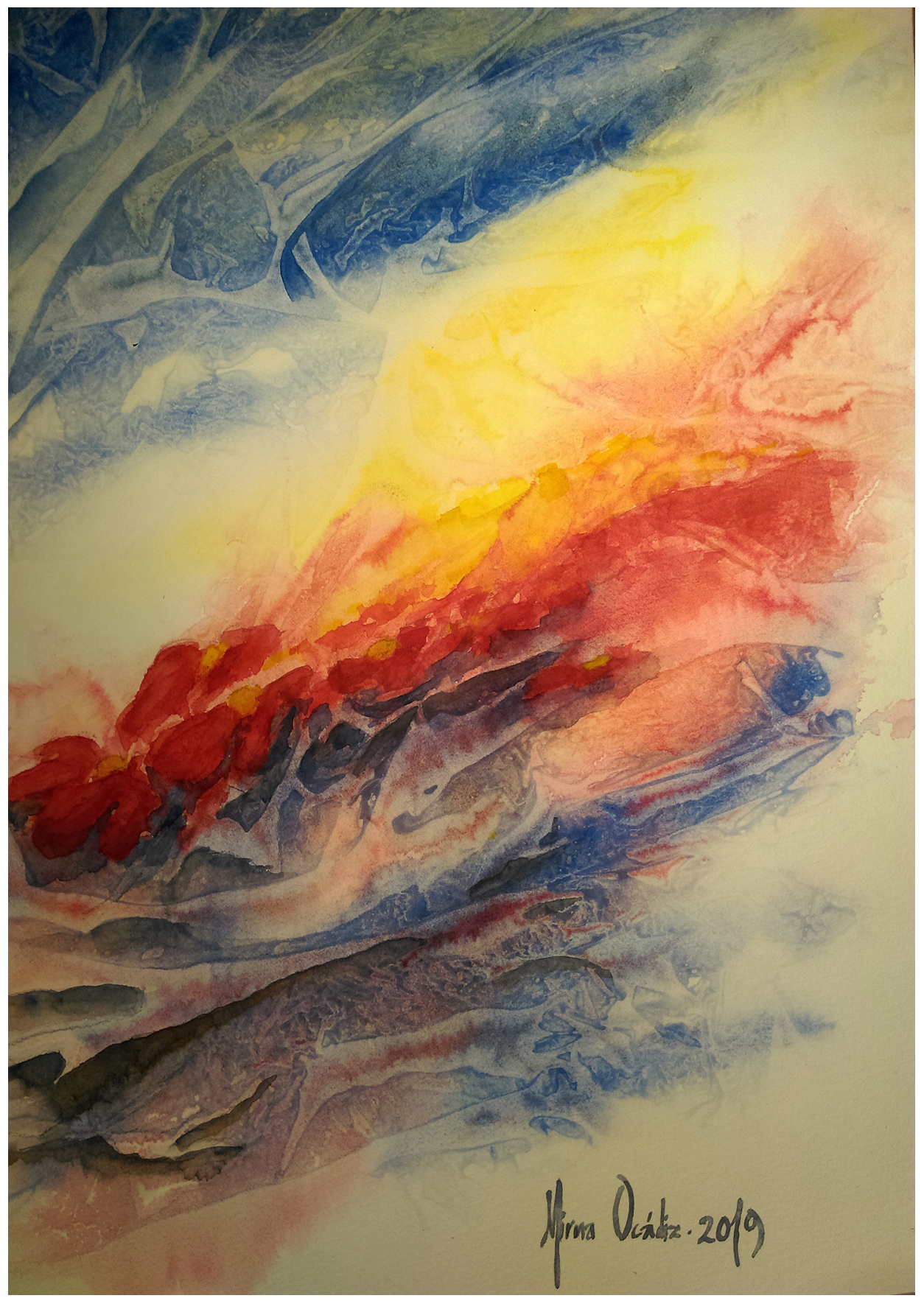

Poesía floral (2019). Acuarela sobre papel de algodón: Mirna Ocádiz-Soto. Prohibida su reproducción en obras derivadas. 
La gama de colores degradados que aparecen en el frontis del paramento de una sección de Copenhague, en Dinamarca, constituye una imagen tierna que describe el temperamento sensible de la pintora. Por el contrario, la pasión desbordada protagoniza las piezas alusivas a los volcanes Popocatépetl, Iztaccíhuatl y Xinantécatl, el último de los cuales es familiarmente llamado por nosotros Nevado de Toluca. La alegoría pictórica de estas formaciones geográficas destaca por la fortaleza de su representación, así como por el manejo de colores extremos que oscilan entre gamas cálidas y frías, y cuyo contexto lo constituye esta especie de mantra formado por texturas que remiten a formaciones fósiles.

Finalmente, debemos subrayar la presencia de paisajes arbolados y flores. Observando la frescura del color, la paleta de la artista se vuelca en la emoción que genera la metamorfosis estacional de la naturaleza, misma que la pintora sabe interpretar mediante la fluidez de su trazo. La libertad de Mirna Ocádiz se refleja en las intricadas mezclas de pigmentos emotivos, cálidos y fulgurantes de energía viva. Su desafío provocador del agua toma forma mediante una suerte de alquimia y nigromancia que lleva a la fusión ideal del arte vivo de la acuarela, la única técnica donde el agua y el pigmento han sido perpetuados para siempre.

\footnotetext{
Mirna OcÁdiz Soto. Acuarelista y arquitecta. Maestra en Estudios Sustentables por la Universidad Autónoma del Estado de México (UAEM), México. Catedrática de Técnicas de Representación, Composición Arquitectónica y Geometría Descriptiva en la Facultad de Arquitectura de la misma universidad. Cuenta con múltiples exposiciones colectivas en México —en los museos "Luis Nishizawa", de la Acuarela, de Numismática, "José María Velasco", de Arte Moderno, la Casa de Cultura de Tlalpan y en la Embajada de Irán en México- y el extranjero - en la Embajada de México en Turquía, en la Universidad de Buenos Aires y en la Universidad de Palermo- - Se le reconoce como acuarelista y promotora de la conservación del arte, la cultura y el medio ambiente, aunado a su actividad dentro de la arquitectura y la pintura.
}

EnRiQue Méndez SosA. Arquitecto por la UAEM con estudios especializados en la conservación de monumentos y zonas históricas. Ha sido Presidente del Colegio de Arquitectos del Estado de México, Secretario del Patrimonio Arquitectónico de la Federación de Colegios de Arquitectos de la República Mexicana, así como catedrático de distintas instituciones. Actualmente, representa la Comisión y Vicepresidencia de Patrimonio Arquitectónico del Colegio de Arquitectos e interviene el Patrimonio del Convento de la Capilla del Panteón en Calixtlahuaca. Ganador de la Bienal de Arquitectura del Estado de México 2011, por la imaguen urbana de Metepec, ha sido, además, curador, guionista de obra plástica y promotor cultural de las artes. 